\title{
7 The political economy of competition and monopoly
}

The "order" of the market emerges only from the process of voluntary exchange among participating individuals. The "order" is, itself, defined as the outcome of the process that generates it. The "it," the allocation-distribution result, does not, and cannot, exist independently of the trading process. Absent this process, there is and can be no "order."

James M. Buchanan (1982b, p. 5)

\section{Competition: static and dynamic}

In the previous chapter, we analyzed the sources and effects of unexpected change on behavior. Regardless of recent attention paid to particular issues or problems of dynamic competition (e.g., advertising), economic theorists still employ static analysis of competition and monopoly. Our critique is directed less to the fruitful positive analysis of competition and monopoly developed in recent years, and more toward conventional normative analysis. We find congenial much of the recent positive analysis of regulation, antitrust and competitive practices. This work includes, inter alia, the "Chicago School of Antitrust" (Posner, 1979), the UCLA-Chicago tradition in industrial organization, and the "New Institutionalism." Indeed, some of our own work belongs in these areas.

Even in this recent work, however, the normative analysis is less appealing than the positive economics. Normative analysis remains essentially static, even when the positive analysis is dynamic. Normative implications are drawn on the presupposition that the market process quickly achieves a preexisting or predetermined equilibrium position (Reder, 1982, pp. 11-13). There is a postulated ontological order, dictated by tastes, opportunities, etc., toward which markets converge rapidly. In the epigraph for this chapter, Professor Buchanan criticized this presupposition. The view criticized there embodies the fallacy of conceptual realism: the belief that mental constructs and purely hypothetical states have an existence in reality. 
There are generally many possible orders or equilibria, depending on the operative institutional processes. Different processes and institutional arrangements are not merely better or worse mechanisms for arriving at the same given end points. Rather, different institutions and attendant processes generate different orders. No one of these needs to be the "correct," "true," or "optimal" order or outcome. There is no institutional or process-independent order, such as is suggested by relating equilibrium positions to tastes, endowments and transformation possibilities (i.e., "data"). That is, there is no order defined apart from the process generating it.

There are, however, systematic relationships between outcomes and processes producing them (Sowell, 1980, pp. 98-100 and passim). "Systematic" does not mean deterministic. Particular features or aspects of social outcomes may be attainable by a number of processes. Policies influencing one outcome or feature will not, however, leave other things constant. Nor do they leave the process itself unaffected.

Systematic criticism of outcomes logically involves criticism of the process producing those outcomes. Similarly, approval of a process producing an order entails approval of the resultant order. For instance, one cannot consistently approve of markets as allocational mechanisms, while objecting to distributional results. In objecting to market outcomes, one is in reality objecting to market processes. In upholding a different allocational-distributional outcome, one is implicitly upholding a different social process. Conversely, sanctioning a social process or mechanism, like the market, logically entails approval of the outcomes (Rawls, 1963, p. 102). "Social choice" involves simultaneous choice of means and affirmation of ends or outcomes.

\section{Uncertainty and markets}

We have argued that economic problems arise only in consequence of unexpected change, i.e., change relative to expectations. In characterizing a disturbance as "unexpected," we focus precisely on those events for which no probability distribution can be meaningfully postulated. Richard Langlois has recently clarified the issue in question by distinguishing between structural and parametric knowledge. In neoclassical economics, "uncertainty" refers to situations in which agents know the structure of the problem but are unsure of the exact value of one or more parameters. As Arrow phrased it,

Uncertainty means that we do not have a complete description of the world which we fully believe to be true. Instead, we consider the world to be in one or another of a range of states. Each state of the world is a description which is complete for all relevant purposes. Our uncertainty consists in not knowing which state is the true one.

(Arrow, 1974, p. 33-4) 
As Langlois has observed:

The agent is implicitly presumed to have an exhaustive list of possible actions and states of the world and, equally importantly, a mean/ends framework relating the actions and states of the world to his utility. We might say that the agent has certain knowledge of the structure of the problem he faces or, to put it another way, that he has perfect structural knowledge. Imperfections in that agent's knowledge extend only to specific parameters of the problem ... He may have imperfect parametric knowledge, but never imperfect structural knowledge; he may acquire parametric information, but never structural information.

(Langlois, 1984, p. 29)

In our terminology, the agent may know typical features but simply be unable to list all possible unique features (see Loasby, 1976, p. 9). He faces an open-ended problem for one of two reasons. First, he may have no relevant experience on the basis of which he could calculate probabilities of outcomes. This situation is characteristic of unique features. Second, the possibilities and their likelihood are not independent of his actions and those of other agents. We have previously emphasized the fact that economic "data" are not objective, in the sense of being independent of human volition and action. Unless one believes in the strictest form of philosophical determinism, this ensures a realm of true uncertainty in human affairs. The imperfection in knowledge is structural and not merely parametric.

As argued in the last chapter, behavioral regularity results not from continuous utility maximization but from rule-following. Rule-following behavior reflects, in turn, a high degree of genuine uncertainty, not certainty. Continuous utility maximization under uncertainty would produce unpredictable results. These results are contrary to conventional wisdom, but this wisdom is not the product of systematic analysis. In a recent article, Ronald Heiner (1983) subjected the conventional wisdom to systematic analysis and sided with the position being articulated here. He observed that

[i]n the special case of no uncertainty, the behavior of perfectly informed, fully optimizing agents responding with complete flexibility to every perturbation in their environment would not produce easily recognizable patterns, but rather would be extremely difficult to predict. Thus, it is in the limits to maximizing behavior that we will find the origin of predictable behavior.

(Heiner, 1983, p. 561)

Decision-makers face the greatest risk of loss (and gain) when forced to adopt new behavioral rules. The adoption of new rules is a discrete, time-consuming learning process, which not all agents complete successfully. We offer the following example to illustrate our point. Good economic theory predicted the general (typical) effects of deregulating airfare: ceteris paribus, real airline 


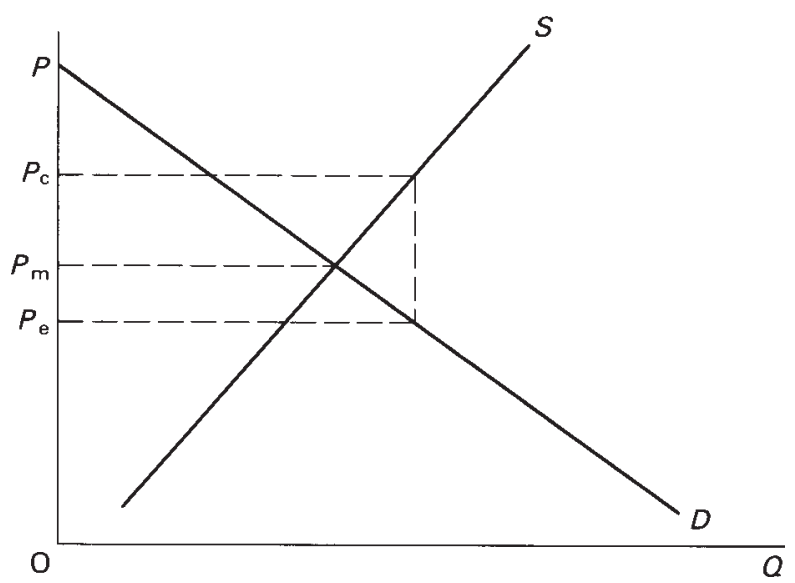

Figure III.2 Airline pricing

tariffs would fall; better resource allocation would result. Careful analysis would also have predicted an industry shake-out. Cartel prices produce excess capacity. With deregulation, excess capacity would predictably be employed providing services that cover incremental but not full costs. In the long run, excess capacity would be removed. Real airfare would rise again, though to a level below the old regulated price. In simple diagrammatic terms $P_{\mathrm{c}}$ was the cartel price, $P_{\mathrm{m}}$ the market or competitive price, and $P_{\mathrm{e}}$ the temporarily depressed price reflecting excess capacity (see Figure III.2).

Airlines have had great difficulty in coping with the transition from a regulated to a competitive environment, in part because most of it took place during one of the most severe of postwar recessions. It is also true however that, to all intents and purposes, airlines had always been regulated. Behavioral rules were geared to survival in a regulated cartel environment. Being the first transportation industry to be deregulated, the airlines had nothing to imitate. The actual experience under deregulation proved surprising to many observers, supporters and opponents of deregulation alike. Among other things, opponents feared the demise of services to small communities. This fear was effectively translated into protection for such services. Deregulation proponents argued that any loss of services would be a price worth paying for improved resource allocation. Few questioned, however, that small community services would not be viable. There was little experience with the economics of such service in a deregulated environment. ${ }^{1}$ Critics and supporters of deregulation alike were proved wrong, as small operators picked up and sometimes expanded small community services heretofore provided by major carriers. "Commuter" lines are the fastest growing segment of the industry.

At the onset of deregulation, it was generally believed that carriers could maximize profits by flying wide-bodied aircraft with high-density seating on well-traveled routes (such as New York-Los Angeles). Based on accumulated knowledge and experience in the industry, there was every reason to expect this 
to be a successful strategy. Yet, the very carriers adopting this strategy (e.g., United Airlines) fared relatively poorly. On the other hand, Piedmont, a regional carrier, is among the most profitable airlines. Its strategy consists of connecting medium-sized cities on routes of 300-600 miles, utilizing smaller jet aircraft. ${ }^{2}$

Airline deregulation illustrates an important implication of the evolutionary theory of the firm. Environmental change renders much accumulated knowledge obsolete. Airlines are now engaged in a trial and error process of discovering and adapting to a new environment. For instance, United Airlines, which had abandoned short "feeder-routes" in favor of longer "high-density" routes, is now reversing its strategy. And it is imitating low-cost interlopers with its cut-rate "Friendship Express" service. ${ }^{3}$

The modern evolutionary theory of the firm must, however, be distinguished from nineteenth-century views of evolution. These emphasized gradualism of evolutionary change, summarized in Marshall's dictum (borrowed from Darwin): natura non facit saltum. For gradual changes, much of our analysis might seem inapplicable or exaggerated. Modern biology now recognizes, however, that evolutionary change is often sudden if not catastrophic. Biologists, who borrowed the concept of evolution from eighteenth-century political economy, have now progressed beyond their social science brethren.

Consider the neoclassical production function. In a world of real time, conventional characterizations of the production function are misleading: "The production possibility set is a description of the state of the firm's knowledge about the possibilities of transforming commodities" (Arrow and Hahn, 1971, p. 53). This is an inadequate representation of what firms know at any given moment. As time passes, technology changes. Firms acquire information about "segments" of various different production functions. They thus know more than could be provided by learning about any one opportunity set. Yet they know less than is suggested by static analysis. They experience only limited ranges of any particular production function, never the complete production set (Nelson and Winter, 1982, pp. 59-65).

We illustrate the practical import of this by considering the effects of a disturbance or innovation. Firms will not move costlessly and immediately to the profit-maximizing point on the relevant production function. In the ensuing selection process, some firms will be eliminated. Some of the losers may be firms that, if they had survived, would have been low-cost producers (ibid., pp. 128-9). If all such change were anticipated, it would be pointless and misleading to talk about "disturbances," much less to analyze the adjustment process. Firms would anticipate and already would have adapted optimally to the change. Indeed, neoclassical economic theory has difficulty explaining why firms (i.e., asset-owning organizations), as opposed to lines of commerce, would ever disappear. In anticipating environmental change, firms would shed unprofitable lines of commerce and enter new ones. Personal computers would be the product of firms formerly engaged in making quill pens. In this world swift application of Occam's Razor would eliminate evolutionary analysis in favor of the hypothesis of continuous utility maximization. 


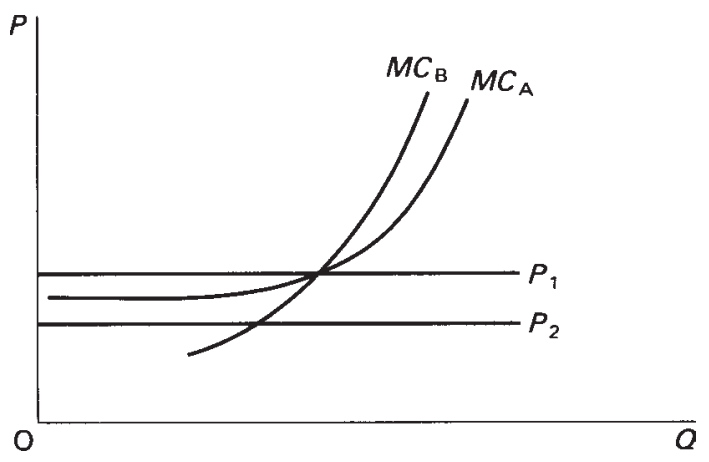

Figure III.3 Firm behavior

Neoclassical theorists are perhaps inclined to reject evolutionary theorizing precisely because it appears superfluous. And it is superfluous in a world of zero information costs. If one does not assume zero information costs, however, then the conclusions of the evolutionary approach cannot be ignored.

Long-run assumptions suffuse standard analyses. Even when economists ostensibly employ short-run analysis, they implicitly assume away informational problems. Transactors are viewed as adapting perfectly and costlessly to postulated disturbances. Standard analytical tools and procedures impose these assumptions on problems. Indeed, our critique is directed less at what is stated formally and openly in textbook and applied analysis, and more at what is implicit and hidden.

We offer a vivid illustration of a piece of positive analysis that surreptitiously employs a long-run equilibrium assumption to deal with a short-run adjustment problem. In that analysis, Professor Stigler "tested" the proposition that firms generally produce under conditions of constant cost (Stigler, 1966, pp. 141-4). He did this by investigating firms' responses to changing demand conditions (see Figure III.3). Confronted by falling demand for their products, firms with constant costs over a wide range $\left(M C_{\mathrm{A}}\right)$ would respond by shutting down. Firms with rising costs over a wide range $\left(M C_{\mathrm{B}}\right)$ would cut back output but continue operating. Stigler found that output restrictions by existing firms dominated plant closings. He accordingly concluded that $M C_{\mathrm{B}}$ better approximates industrial cost conditions than $M C_{\mathrm{A}}$.

What Stigler actually did was conduct a multiple test of (1) cost conditions, (2) price-taking behavior and (3) equilibrium conditions. He implicitly assumed that competitive firms facing constant long-run costs would also face constant short-run costs, as well as be price-takers outside of long-run equilibrium. Arrow (1959) has demonstrated the implausibility of the second and third conditions. Without bringing in most of the considerations already discussed, we could adduce an explanation more plausible than Stigler's. Let us first stipulate that in fact cutbacks predominate over shutdowns. We assume, however, that, à la Arrow, firms confront downward-sloping demand curves in 
the short run. We can then explain the empirical results, even in situations in which marginal costs were constant across all runs. Our hypothesis is accordingly more robust than Stigler's, since it applies to situations of both constant and increasing costs. Further, we can illuminate why even competitive firms might keep prices constant in the face of falling demand (a phenomenon not without examples). This latter would occur, for instance, in the case of linear demand curves and constant costs, if demand changed equiproportionately at every price.

Perfect-adaptation models are implausible, yet economists adhere to them. Often, they do so because the alternative appears to be theoretical nihilism. Since nihilism is not the alternative, it is time to reexamine an essentially untenable position.

\section{Optimal policy}

Standard welfare economics deduces a set of conditions that must be satisfied in order for there to be optimal resource allocation (Baumol, 1965, pp. 356ff.). Stated most generally, these conditions demand equality at the margin of social benefits and costs. This approach is applied to such issues as externalities, monopolies and tariffs. Under idealized conditions, markets yield an optimal allocation of resources. If the unfettered operation of markets produces a divergence between social benefits and costs, be it in the form of externality, monopolistic output restriction, or whatever, this is attributed to "market failure."

The theory of economic policy prescribes three main approaches to dealing with market failure: taxation, regulation and antitrust. There is usually a choice between two of these general approaches. For instance, antitrust policy is largely inapplicable to externality problems. Similarly, though a few observers have proposed using tax policy to influence monopolists, policy-makers generally weigh choices between regulation and antitrust for monopoly problems.

For most major questions, there is a large literature on choice of policy instruments. There is also typically a substantial literature on various methods of implementing a particular policy, e.g., taxation. Within and among alternatives, the criteria applied to policy choices are those of general equilibrium welfare theory. Policy judgments are typically made on the basis of presumed differences in informational requirements and transactions costs. This literature frequently begs important questions and exaggerates the differences among the three policy approaches. We argue our position by reference to two concrete examples: control of pollution, and control of monopoly.

\section{Pollution}

Ronald Coase (1960) challenged the Pigovian policy of using taxes and subsidies to control pollution, arguing that taxation of externalities would not generally result in optimal resource allocation. He criticized reasoning 
that presumes producers of externalities cause costly interactions and ought automatically to be taxed. "Victims" of pollution may in practice be least-cost avoiders of harm. In setting a tax at an apparently optimal level, authorities may thus effect an uneconomic use of resources. Coase focused here on the information requirements for implementing optimal policy. He suggested that preferred solutions generally arise when parties negotiate among themselves to rearrange property titles. If high transaction costs preclude negotiations, Coase suggested carefully drafted liability rules as a solution. These rules ought to take account of comparative costs of avoiding harm, as well as presumptions regarding the identities of the highest-valued users of resources. Coase further argued that cases of apparent market failure were often the effects of statutory exemptions from standard liability rules. His article spawned the modern property rights approach to externalities and to legal questions generally.

Proponents of the Pigovian tradition were slow in responding effectively to the Coasean challenge. Baumol's (1972) reply was, however, an articulate case for the classic taxation alternative. It is, moreover, explicit about informational assumptions that are usually implicit, thereby revealing problems inherent in all theories of optimal taxation. The following quotation succinctly states the case:

Despite the validity in principle of the tax-subsidy approach of the Pigovian tradition, in practice it suffers from serious difficulties. For we do not know how to estimate the magnitude of the social costs, the data needed to implement the Pigovian tax-subsidy proposals. For example, a very substantial proportion of the cost of the pollution is psychic; and even if we knew how to evaluate the psychic cost of some one individual we seem to have little hope of dealing with effects so widely diffused through the population.

This would not be very serious if one could hope to learn by experience. One might try any plausible set of taxes and subsidies and then attempt, by a set of trial and error steps, to approach the desired magnitude. Unfortunately, convergence toward the desired solution by an iterative procedure of this sort requires some sort of measure of the improvement (if any) that has been achieved at each step so that the next trial step can be adjusted accordingly. But we do not know the optimal combination of outputs, so we simply have no way of judging whether a given change in the trial tax values will then have moved matters in the right direction.

These difficulties are compounded by another characteristic of externalities which has already been mentioned - the likelihood that in the presence of externalities there will be a multiplicity of local maxima. Consequently, even if an iterative process were possible, it might only drive us toward a local maximum, and may thus fail to take advantage of the really significant opportunities to improve economic welfare (Baumol, 1972, p. 316). 
Theories of optimal taxation ignore the fact that information necessary for their implementation will always be missing. Cost is subjective, and forward-looking. As such, cost is not a directly observable magnitude. There is, further, no calculational mechanism with which to measure gains and losses from alternative levels of taxation. Finally, to extend Baumol's argument, the data of the problem are not constant. This alone negates any iterative solution. During a time-consuming iterative process, data change. An iterative taxation system has neither a calculational mechanism, nor the entrepreneurship driving market behavior.

Baumol adduced an argument almost isomorphic to the more general argument against nonprice resource allocation. Mises and Hayek first stated this more general argument as a critique of "socialist," i.e., nonprice, resource allocation. Absent a system of markets, especially factor markets, transactors are unable systematically to calculate benefits and costs of various actions or production plans. The initial socialist response or "solution" was to set price and marginal cost equal. But this response is an evasion of, not a solution to, the informational and calculational dilemma posed by Mises and Hayek. How could a central planner ascertain the subjective cost or marginal value of an action to millions of citizens? It is true, of course, that if marginal cost and consumer preferences are institutionally independent, and if information about these is costlessly available, then marginal cost pricing is equivalent to the competitive "solution." The Mises-Hayek critique questioned these assumptions, not the conclusion of the valid but unsound socialist argument. In fact, it was the Austrians, particularly Wieser, who had long before demonstrated the logical validity of that argument.

The next socialist solution was to suggest an iterative process for allocating resources. Arbitrary prices would be set and then adjusted in response to observed excess demands. Hayek replied that, without real markets for factors, profits and losses would be impossible to calculate. In a socialist economy, there would be no factor owners to weigh (internalize) the risks and rewards of alternative production plans. The absence of private property rights in capital (if not in other factors) is the essential characteristic of socialism. Accordingly, there would be no competitive bidding process producing offers to internalize. Further, without title to residual claims, socialist managers of resources would lack incentives to act entrepreneurially in discovering opportunities.

The force of these arguments is measurably increased when one recalls that Mises and Hayek always presumed that significant changes in data typify all economies. Though they had by then abandoned the goal of abolishing markets, the advocates of socialism ignored the informational issues and assumed static conditions in their response. Somehow, however, texts repeat the myth that Mises and Hayek were "answered" (see Reder, 1982, p. 4).

In the Mises-Hayek analysis, socialism is intervention carried out systematically in all markets. It substitutes nonprice and nonmarket allocation for pricing and market institutions. Particularistic intervention at the micro level 
is socialism writ small. To paraphrase Robertson, market interventions generate islands of calculational chaos in a sea of markets. It is a misnomer to speak of "calculating" the benefits and costs of intervention, when the evident effect of such intervention is interference with the market's calculational procedures. Consider the use of taxes to influence output levels (as opposed simply to raising revenue). Taxes are often viewed as substitutes for intervention by regulation or other means; yet the two alternatives are more similar than not.

If a tax rate is to be optimal, policy-makers must know the optimal level of the taxed activity (e.g., discharging effluents into a river). If that were known, however, a regulatory system prescribing this level of activity would seem neither inferior nor more costly than the tax alternative. The informational requirements of taxation and regulatory approaches are formally identical, a point made evident in the Baumol quotation above. And the informational requirements for optimal regulation are simply those for optimal nonprice resource allocation. There can be no theory of optimal regulatory (taxing) behavior until there is a theory of nonprice resource allocation that actually addresses the original Mises-Hayek argument.

Taxation of an activity is often proffered as a "market" approach, which substitutes for a regulatory or interventionist approach. Economists mislead themselves and their readers, however, by speaking of "tax prices." The only shared features that taxes have with prices is their dimensionality. Taxes do not result from a market process, nor do they reflect allocational decisions of resource owners. Taxes affect prices but are not themselves market prices measuring an economic trade-off at the margin. In other words, taxation is a method of intervening, not an alternative to intervention or nonmarket allocation. Absence of markets and improperly specified property rights do generate economic problems. The very absence of relevant markets, however, implies the absence of any ability to acquire the very information needed to correct the problem. If markets are not providing signals to transactors on all costs of an action, policy-makers will also lack this information. Moreover, even were they to possess the required information, political decision-makers face different incentives than do entrepreneurs.

Let us hasten to point out what we are not saying. By itself, the foregoing is neither an argument for unfettered markets, nor a criticism of any kind of intervention. (Indeed, the foregoing is strictly positive analysis.) We would, however, criticize any argument that a cost-benefit calculus can be applied to such intervention. We ourselves are sympathetic, for instance, to judicial rectification of tortious acts performed by polluters. But our support of judicial remedy rests on a belief in principles of corrective justice. We would not pretend that social utility is being maximized by the use of common law remedies. We would be quite pleased, however, if the victim were made whole. Pursuit of the latter strikes us as a worthy enough goal even if it falls short of an artificial welfare ideal that is, in any case, unattainable in principle. 


\section{Antitrust}

For a variety of perceived economic problems, antitrust policy represents an alternative to a classic regulatory solution. For instance, as deregulation of the transportation sector has occurred, Congress has removed the antitrust immunity of firms engaged in surface and air transportation. The discipline exerted by the antitrust statutes has been substituted for that of the regulatory process. Many economists would favor this procedure generally, because, within a framework of rules, it seems to leave outcomes to market processes. While many individual antitrust policies, such as on resale price maintenance and prohibitions on vertical mergers, have been criticized, there is substantial agreement among economists on the need for a policy on horizontal mergers and collusion.

This support for antitrust cuts across the political spectrum, although proponents of market solutions must be ambivalent toward the use of antitrust laws. Antitrust may be a preferred substitute for activist regulation, but it is still an intervention. Antitrust policy diminishes or eliminates the market value of asset titles, and circumscribes private property rights. The tension between support of a market-oriented policy and advocacy of antitrust is heightened by the realization that antitrust law has little basis at common law. ${ }^{4}$ It is not the development of reorganized legal principles, like the law of torts and contract, so much as an application of administrative law. Epstein (1982) has recently argued that antitrust policy is broadly inconsistent with common law doctrine and principles of corrective justice.

Our concern in this section, however, is with the economics of public policy toward monopoly. We associate any problems with standard economic analysis rather than with defects in legal reasoning or the political process, though the latter two factors are also undoubtedly sources of difficulties. We focus on informational issues suppressed or ignored in standard formulations, issues that infinitely complicate the process of utilizing economic analysis in antitrust policy. We suggest that the informational requirements for antitrust policy are closer to those for a regulatory approach than is generally recognized. These requirements are qualitatively the same as for other forms of nonmarket resource allocation.

Competitive values or allocations do not exist "out there," independently ascertainable apart from actual market results. Competitive prices and cost can be consistently defined only as the outcomes of competitive processes. There are not competitive results unless there is competition. As Buchanan reminds us, the "order" produced by competition "is, itself, defined as the outcome of the process that generates it ... The allocational-distributional result does not, and cannot, exist independently of the trading process." Without competition, there is no reference point to which comparisons with real-world results can be made. In absence of competitive markets, economic theory cannot tell us what is optimal. Still less can theory yield detailed predictions of what firms would have done under competitive conditions. Antitrust economics 


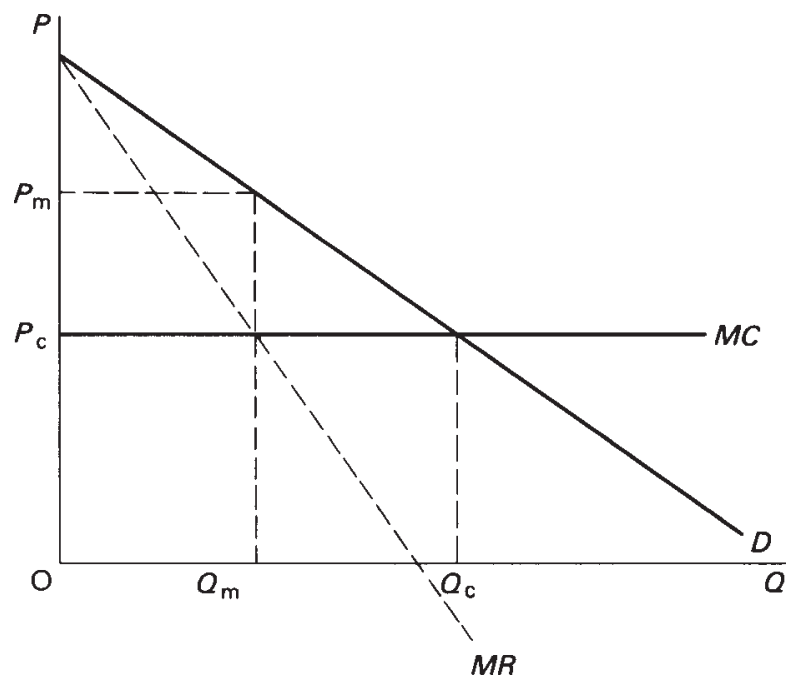

Figure III.4 Market pricing

assumes, however, that policy-makers can do just this - or, at least, it assumes that they can move us in the correct direction. Yet even the latter is doubtful.

There are a few abstract distinctions that can be posited about the outcomes of monopolistic as compared with competitive markets. Ceteris paribus, monopolists produce less at a higher price. This is true, however, virtually by definition. In a static framework, the theory is pellucidly clear and deterministic. Problems arise, however, when it is applied to actual market arrangements. We refer to the familiar diagram representing monopolistic equilibrium (Figure III.4).

As is illustrated in the figure, a monopolist is treated as knowing or being capable of discovering competitive equilibrium. The monopolist chooses, however, to maximize profits by producing at $Q_{\mathrm{m}}$ instead of $Q_{\mathrm{c}}$. He faces the same production possibilities, demand, etc., as would exist in a competitive environment. Regulation or antitrust can move the market from $\left(P_{\mathrm{m}}, Q_{\mathrm{m}}\right)$ to $\left(P_{\mathrm{c}}, Q_{\mathrm{c}}\right)$. If, however, we relax the assumptions of standard theory, these policy conclusions appear much less certain. Indeed, outside of long-run equilibrium, it is not clear that we can distinguish conceptually between the behavior of competitors and monopolists.

As Arrow (1959) first made clear, the characteristics associated with perfect competition would only eventuate in long-run static equilibrium. In "Toward a Theory of Price Adjustment," Arrow (1959, p. 42) presented "the theoretical analysis of the decisions as to price." We do not normally associate pricing decisions with competitors, because neoclassical theory treats prices parametrically in competitive models. As Arrow (p. 46) noted, however, in disequilibrium there is no reason to believe that Jevons' Law of One Price would 


\section{The economics of time and ignorance}

apply. He associated disequilibrium with an imbalance between supply and demand. If, for instance, demand exceeds supply at a disequilibrium price, then, so long as production is time-consuming, entrepreneurs will discover that they can raise their prices without losing all their customers to competitors. In other words, each entrepreneur will realize that he is in the position of a profit-maximizing monopolist. By a trial and error process, the entrepreneur seeks out the price-quantity combination that maximizes the profit of his competitive firm. In this disequilibrium process, competitive firms confront downward-sloping demand curves.

Arrow chose to model a dynamic process using a static model: that for a neoclassical monopolist. We rejected this ploy because it captures one feature of the competitive process - the search for a profit-maximizing price - at the cost of losing sight of all the other features characterizing competition. As we argued in previous chapters, the attribution of "equilibrium" to reality (as opposed to a model) is an egregious example of the fallacy of misplaced concreteness. The world is never "in equilibrium." In Chapter 6 we suggested that the appropriate response is to abandon formalism and static assumptions at the stage of modeling the system (rather than in applying the model). Professor Arrow adopted the alternative strategy. In this instance, his more conventional approach does highlight one salient point. If the conditions of perfectly competitive theory are not met - and they never can be fulfilled in reality - then formal economic theory cannot distinguish between the behavior of a monopolist and that of a competitor. It is not simply that the theories of competition and monopoly are difficult to apply to the complex fact-patterns of antitrust cases: rather, the theories are analytically indistinguishable.

Arrow compressed the competitive and monopolistic cases into one by arguing that competitors will often confront the same pricing problem as monopolists. Elsewhere, O'Driscoll (1982) argued that monopolistic markets are more like competitive markets than is true in neoclassical models. If all costs are properly measured, than a monopolist will price equal to cost at the margin. This is true even though he confronts a less than infinitely elastic demand curve.

Regardless of which tack one takes (Arrow's or O'Driscoll's), the analysis undermines the sharp distinction between monopoly and competition characteristic of formal neoclassical theory. This is not to suggest that the two market types cannot be sharply distinguished. In the next section, we present an alternative approach to a theory of monopoly. Neoclassical economics does not, however, provide this distinction.

Not only does antitrust policy lack the sound theoretical foundations it claims for itself, but, as a practical matter, the informational requirements needed to implement it will never be attainable. It is true, of course, that policy-makers do not look at the relationship between price and marginal cost in antitrust cases. Marginal cost is unobservable, a fact apparent even in nonsubjectivist formulations of cost theory. Rather, policy-makers look at other 
characteristics that they believe distinguish competition and monopoly. Not surprisingly, we question this procedure.

Put simply, no one knows what a competitive market would look like in the absence of competition. This is surely the essential lesson of a process view of competition. The point is driven home by considering again the course of one episode or instance of deregulation: the airline industry. One of the most striking results of demonopolizing the airline industry is the greater degree of product heterogeneity and the larger dispersion of fares. Neither result would be predicted by neoclassical theory. Each result is fully consistent with a process view. Indeed, the greater diversity of product offerings is a prediction of a process theory of competition, as we indicated in Chapter 6 .

As regulations have been relaxed, airlines have increased the diversity of their services. Cut-rate (less than full-fare coach) service has certainly increased. Imitating low-cost interlopers, traditional trunk carriers have introduced "nofrills" transportations; for instance, United Airlines has reconfigured jets with lighter-weight seats so that more can be fitted on each plane. But the range of services and classes has also increased, fine-tuning output to the diversity of consumer preferences. The introduction of business class is one example of satisfying the diversity of consumer preferences.

Interloper airlines are frequently responsible not only for the low-cost service, but also for the greater diversity of offerings. This reflects their greater orientation toward marketing. Newcomers know only a relatively competitive environment. Existing trunk carriers had adapted to a regulated environment with well specified monopoly rights. The trunk carriers were superb at public relations and weak on marketing. In regulated environments, firms are concerned overwhelmingly with explaining or justifying existing industry practices. Competitive firms are prone to upset shopworn practices. In the process, they develop other skills.

Airline deregulation has revealed accumulated inefficiencies in the regulated environment. New carriers not only have lower factor costs (labor and capital), but also use absolutely less of almost all factors. Greater flexibility in utilizing labor permits firms to have a smaller labor pool. For instance, New York Air utilizes workers interchangeably (e.g., reservation clerks and stewardesses). Likewise, 30 minutes used to be a quick turnaround time for aircraft; now, Southwest Airlines (a Texas-based carrier that was never regulated) can unload and refill a plane in 10 minutes.

Consideration of the effects of airline deregulation reveals that monopolized (or cartelized) markets differ from competitive ones in several, not just one, dimension. There are systematic differences besides pricing disparities between the two. Monopolists tend to produce the wrong goods from the perspective of consumers. There is lack of diversity and, as we suggest below, a tendency to lower-quality goods in monopolized markets compared with a competitive environment. These effects receive short shrift in neoclassical analysis, because of the stringent assumptions of these models. In the latter, the good is a given and cost conditions are data. Price is the only dimension 
in which monopoly can differ from competition. This does not merely reflect simplifying assumptions, but goes to the heart of the static conception of competition. Prices are statements of rates of trade-off among commodities, rather than reflecting discrepancies among individuals' plans and the existence of profit opportunities. ${ }^{5}$ Further, price is the only market-signaling mechanism. This leaves price the only control variable, and relative scarcity values the only endogenously produced information. Tastes, for instance, are and must be exogenous.

The multifaceted effects of monopoly were understood by classical political economists (see Smith, 1937, pp. 147; 575-6; 595-6). Their insights on nonprice effects of monopoly were lost as neoclassical economic theory was formalized, to survive only in what Nelson and Winter (1982, p. 46) have described as the "appreciative" theory of competitive adaptation that we teach to undergraduates. This informal theory of price bears little relation to formal theory.

In a process analysis of competition, firms must, inter alia, discover consumer preferences. Competition provides incentives to undertake the search, incentives largely lacking with monopoly. ${ }^{6}$ In presenting our own approach to monopoly, we clarify and sharpen this analytic point. First, however, we consider the case of telecommunications policy.

American Telephone and Telegraph Company (AT\&T) long beguiled observers with its apparent efficiency, innovation and orientation to consumer preferences. It seemed to be a monopoly that worked. In reality, deregulation has revealed deficiencies in all three respects. In analyzing AT\&T, economists failed to adopt a systematic opportunity-cost approach. The question should never have been AT\&T's performance relative to the US Post Office, or to foreign telephone services. The question is, and should have been, AT\&T's performance relative to that of firms in a deregulated environment.

Deregulation came first to the office telephone market. Western Electric (AT\&T's manufacturing subsidiary) rapidly lost its share of the market to competitors because of inferior technology. As the home equipment market opened up, a similar process began taking place. Indeed, a great deal of equipment now sold in Bell System retail stores was not made by Western Electric.

AT\&T's use of capital resources is extravagant compared with its competitors. For instance, MCI's microwave towers are smaller and cost considerably less than AT\&T's. Recent closings of Western Electric plants apparently signal recognition of technological backwardness. Engineers and scientists may find it difficult to think of AT\&T as technologically behind the times. AT\&T is well known for its basic research. Economists, however, ought not to be perplexed. Beneficence in support of pure research is irrelevant: ability to bring technology to the bottom line is what counts. Deregulation in telecommunications is repeating a familiar pattern. Existing firms, heretofore possessing statutory monopolies, must catch up with interlopers.

We have argued that the effects of monopoly are more complex than a price-cost divergence. Some costs tend to be higher, others lower. Output 
characteristics are not as well attuned to consumer preferences as on competitive markets. We have suggested that these differences can be related systematically to the different property rights possessed by monopolists and competitors. In the final section, we develop some of our theoretical points in greater depth. We also consider some policy options.

\section{Property rights theory of monopoly}

In this final section, we make explicit our conceptualization of the differences between monopoly and competition. In so doing, we present elements of a theory of monopoly. There is obviously more than one way to distinguish among market types. In fact, O'Driscoll (1982) presents two distinct conceptualizations of monopoly that are consistent with an overall subjectivist analysis. We believe that the one approach offered here is both fruitful and consistent with recent developments in other areas of economics.

We define monopoly as an enforceable property right in a product or market share. A monopoly right can encompass a great deal of economic activity or apply to a wide geographic area; or it can be narrow in scope and circumscribed geographically. When monopolists holding market shares or operating jointly in a territory or market cooperate, we call this situation a "cartel." Cartels are shared monopolies. There is thus no separate oligopoly theory.

Monopolistic and competitive markets are characterized by different property rights structures. Variations in rights structures generate relevant incentive effects. Competitive firms do not engage in rivalrous activities because they have a preference or predisposition to compete. Rather, they face constraints compelling rivalrous behavior merely to maintain, much less to expand, existing market shares or profits. This analytic approach is consistent with the emphasis on property rights that has evolved in other economic areas (e.g., in externality theory and in the analysis of exploitable resources).

A competitive firm has no ex ante property right in a share of the market or a portion of market demand. Each period, it must expend resources to reacquire market share, sales, profits, etc. Other firms are in the same position. Actions leading to previous success can be imitated, reducing their expected payoff. This stimulates expenditure of resources to find ways to do as well or better than before. It is this process, only sketched here, that we describe as "rivalry." It occurs because of the structure of property rights.

Competitive firms have no property rights or titles to a market share, and certainly none to profits. In a market with free entry and no restriction on competitive practices (e.g., no advertising bans), past market shares yield no ex ante guarantee of future market performance. Observed market shares are ex post outcomes. Absent a secure property right, they tell us little about future market shares.

Firms owning secure property rights to market shares would be foolish to expend resources in the same manner as competitive firms. For instance, a 
monopolist will do less of the kind of innovation stimulated by competition. Instead, he will devote resources to innovating in public and governmental relations. These expenditures help secure his property right, though producing little or nothing of value to customers. This is a kind of inefficiency that until recently has escaped the notice of conventional monopoly theory. It exemplifies the kind of specific costs incurred by monopolists. ${ }^{7}$ There are other costs incurred by competitive firms but not by monopolists. Many of these are expenditures made necessary by the actions of rivals. They are exemplified by advertising and marketing costs that are spared a monopolist. Some critics of competition characterize them as waste. Other issues aside, we see that the alternative is not necessarily less, but different costs incurred. Costs incurred in the competitive process, however, produce some expected payoffs for consumers.

Let us return to airline deregulation to illustrate the latter point. Regulated trunk carriers invested in excess capacity under CAB regulation. Because they faced supra-market rates, they flew too many flights and utilized larger than necessary aircraft. This investment was profit-maximizing, but wasteful from the perspective of consumers. Excess capacity enabled airlines to capture peak-load traffic, generating monopoly returns. Aircraft were full or nearly so only a relatively small portion of the time. During those periods, revenues were far above costs. In normal times, capacity was underutilized. Losses incurred during normal periods were less than monopoly returns in peak periods. With lower competitive fares, firms cannot afford this procedure. In the new competitive environment, airlines better apportion their resources to average demand. Peak-load pricing substitutes for excess capacity.

To an outside observer, it is "obvious" that resources were being wasted under $\mathrm{CAB}$ regulation. And there was inefficiency from the consumer's perspective, the only one that should matter in market analysis. For the monopolist, however, the utilization of capital was profitable. Property rights analysis focuses on the source of the perverse effects of private profit-maximization. These effects derive from the monopoly right itself, which insulates the producer from competitive pressures.

One could tell our story somewhat differently by characterizing airlines' behavior as rational responses to regulatory actions. In the end, this would be the same story. Regulation is not adventitious, but is the mechanism by which a monopoly right is enforced if not secured. Without regulation, the right is unenforceable and thus economically irrelevant. Property rights analysis focuses on issues like the specification and enforcement of legal entitlements or rights. This approach raises the question of how a right is acquired and enforced. Standard neoclassical analysis is weakest on this issue. Even property rights theorists have failed to extend their analysis systematically to monopoly theory. Yet the questions raised in this literature have special importance to the monopoly question. Especially in the transportation area, regulatory commissions were the relevant enforcement mechanism of monopoly rights. 
There is good reason for subjectivists and process theorists to adopt a property rights theory of monopoly. This can be best understood by recalling the introductory discussion in this chapter. We related outcomes to the processes generating them. Institutions play a crucial role in shaping social processes. Changes in fundamental institutions will generate different economic processes, and thus different outcomes. We view property rights as a fundamental institution, partly determining the nature of economic processes. Property rights analysis focuses on the structural environment of economic processes. Langlois has gone so far as to characterize modern process theory as the "New Institutional Economics," though with an important caveat:

The problem with the Historical School and many of the early Institutionalists is that they wanted an economics with institutions but without theory; the problem with many neoclassicists is that they want economic theory without institutions; what we should really want is both institutions and theory - not only pure economic theory informed by the existence of specific institutions, but also an economic theory of institutions.

(Langlois, 1982a, pp. 16-17)

We have not attempted to articulate a theory of institutions. We have, however, emphasized the importance of specifying the property rights and relevant legal rules in any economic theory of competition and monopoly. Failure to do so leads to incomplete and erroneous analysis. To illustrate this latter point, we consider the central issue of neoclassical monopoly theory - the entry question.

Monopoly yields a net revenue, yet by assumption no entry occurs. Monopoly rent, and the associated "deadweight loss," are unexploited profit opportunities. These ought not to persist; their existence ought to lead to their own demise.

Neoclassical monopoly theory postulates but does not explain the existence of monopoly. It leaves the entry problem unresolved. Traditional entry barrier arguments have lost their appeal in the face of criticism (Demsetz, 1982). Some even believe that they are all but abandoned (Posner, 1979). In any case, like many other authors, we are unconvinced by traditional entry barrier models. Generally, the models suffer from one of two failings (or both). Either they identify a real scarcity as a "barrier" (e.g., advertising or capital costs), or they identify a cost already incurred by existing producers as barriers to new entrants (e.g., start-up costs). Information and capital costs reflect real scarcities. If potential entrants cannot afford to incur the full costs of competing, then this merely indicates that entry is not profitable and ought not occur. Start-up costs reflect a particular kind of information cost. Among other things, new firms typically must operate at a loss, even with negative cash flow, for an initial period. This requires making an initial investment, no different in principle from all other capital expenditures. An initial outgoing 
in early periods is compensated by returns in later periods. At root, treatment of a subset of capital or information costs as suspect or unnecessary reflects a belief that these costs are not, or ought not to be, real. We know of no way of conjuring away either these costs or the informational factors that they reflect. In any case, positive analysis must take perceived costs as they exist.

For reasons not entirely clear, economists are impatient about the existence of profits but view with equanimity models postulating the persistence of monopoly returns. In positive and normative analysis, entrepreneurial profits are merely "short-run" phenomena; the analysis quickly moves to the long run. Modern theories of efficient markets and rational expectations explicitly treat profits as random events of transient duration. Profits cannot exist for more than one period, since this would permit agents to respond and obtain, in effect, something for nothing - a return over cost. At the same time, neoclassical monopoly theory postulates the existence of supra-normal returns period after period. (The "period" in the industrial organization literature is certainly a year in duration.)

Profits represent no conundrum for a process view of economics. Changing economic conditions are continuously generating new profit opportunities (and eliminating old ones). Asymmetric information is an integral part of subjectivist analysis. The "man on the spot," the specialist, has superior information. He can exploit or profit from this superior information. Over time, others will discover the information. If he has not already fully exploited the profit opportunity, it will be competed away. Adam Smith's view of the link between specialized knowledge ("trade secrets") and profit was basically sound: "Secrets of this kind ... can seldom be long kept; and the extraordinary profit can last very little longer than they are kept" (Smith, 1937, p. 60). What must be added to Smith's observation is the recognition that markets continuously present entrepreneurs with new menus of profit opportunities, even though each opportunity eventually disappears.

In the absence of a secure property title, persistent monopoly gains ought to be as troublesome to neoclassical economists as they are to process theorists. Not only the monopolists' gain, but also the associated "deadweight loss" represent unexploited profit opportunities (O’Driscoll, 1982, pp. 199204). These potential gains are not the result of temporary disequilibrium, asymmetric information, or any other information problem. Monopolies are obvious features of the economic landscape, their gains revealed for all to see. They ought to represent especially ripe targets for entrepreneurial action. Gains from invading a monopolist's turf are inherently less speculative than ordinary profit opportunities. Profit-maximization by monopolists almost invariably creates relatively secure profit opportunities for interlopers. If, for instance, the monopolist price discriminates, then this very pricing policy guarantees arbitrage profits. If the monopolist has a uniform pricing and service policy, then there are typically high-valued customers who would prefer a superior service at a higher price. In the latter case, the interloper "skims the cream" off the top of the business. 
As with nineteenth-century railroad monopolies, the two situations can go hand in hand. The railroads engaged in value-of-service ratemaking but tended to provide roughly uniform service to all shippers. With the rise of motorized trucking, railroads first lost the high-valued customers. Trucks offered more flexible service, which better met the scheduling demands of shippers placing a relatively high value on timely delivery. Moreover, trucking is inherently less prone to the kind of damaged shipment problems that result from coupler-slack in rail transportation. In the end, railroads were left with low-valued business, like hauling shipments of bulk commodities and agricultural produce. Yet sunk investments and common-carrier responsibilities left them with overhead costs not recoverable from revenue generated by remaining business. Losses on passenger service added to this problem in many cases. Only the recent deregulation of railroad rates has halted the 60 -year decline of rail freight transportation.

Monopoly gains simply cannot persist in the face of determined profitseeking entrepreneurs. If a monopoly position is to be maintained, the monopolist must possess a secure title to, or property right in, a share of the market. Only the state can secure such titles and grant such property rights. Applied economic analysis of monopoly should, accordingly, identify and explicate the legal or governmental source of that monopoly as its first order of business. This position does not derive from a tautological definition of monopoly as a right or privilege granted by a governmental unit: it is, rather, a conclusion of economic analysis.

The property rights approach enunciated here is basically the view of monopoly at common law, as restated by Blackstone (1803, p. 159) when he described monopoly as

a license or privilege allowed by the king for the sole buying and selling, making, working or using of any thing whatsoever; whereby the subject in general is restrained from that liberty of manufacturing or trading which he had before.

The common law view was absorbed into American law, being clearly stated in the Charles River Bridge case. ${ }^{8}$ The court there defined monopoly as "the withdrawal of that which is a common right from the community and vesting it in one or more individuals, to the exclusion of all others." The story of how the common law conception of monopoly was transformed into the modern statutory conception is an intriguing one, which, however, goes far beyond the subject of this chapter (but see Bork, 1978, pp. 15-49; and O'Driscoll, 1982). Our point here is theoretical: monopoly rents can persist only if legally protected. From the perspective of a property rights theory, neither antitrust nor regulation is an appropriate vehicle for controlling monopolies. Regulation and perhaps antitrust policy are sources of monopoly power. Deregulation and repeal of legal protections are the appropriate responses. Surface and air transportation are not special cases, but are paradigmatic examples of monopoly in practice. 
There is no question that distinctions between ordinary private property rights, which are necessary for decentralized economic organization, and monopoly rights are often fine ones. Patents and copyrights are tough cases. Traditional arguments in their favor are well known. Though we are suspicious of some of these, we are by no means prepared to argue here forcefully and universally against either patents or copyrights. From a property rights perspective, however, the time is ripe for reconsidering the case for both patents and copyrights. Since Sir Arnold Plant's critique of patents, there has been comparatively little attention paid by property rights theorists to the subject (but see Littlechild, 1979, pp. 42-3; and Rothbard, 1970, pp. 652-60). The use of video cassette recorders has raised law and economics issues in copyright law, which invite reconsideration of its basic premise.

Relative to neoclassical formulations, property rights theory is more appreciative of the economic usefulness and significance of contractual restrictions and "restraints" on market participants. The theory emphasizes that economic activity can occur only in an institutional and legal setting. The process of contracting and legally binding oneself is a prelude to almost any economic relationship. A market economy is a complex web of vertical and horizontal restraints without which economic activity would be impossible. These contractual relationships, which constrain some activities, do not inhibit but rather make possible competition (as a process). In almost any purchase of an existing business, for instance, the buyer will want some assurance that the seller will not immediately reenter the market as a competitor. The seller is not injured by permitting such contracts, but is helped: he can obtain a higher price for his business. To the degree that resources are thereby moved to a high-valuing user, consumers are also helped. Yet, after the fact, the seller of the business is restricted and consumers are seemingly denied a potential competitor. Such contracts are taken to be restrictions on competition. Yet these and other contractual restraints generally make possible the formation and recombining of assets and resources that is the driving force behind competition and economic progress. Indeed, to the extent that individuals are attracted to a market by the realization that they can easily sell their enterprise, these restraints foster competition. There is no trade-off between values. Contractual freedom is a necessary condition to obtain the value of competition.

Where we would draw the line, and where we think it must be drawn, is between contractual and third-party imposed restraints. Questions of political rights aside, third-party restraints have significantly different effects than those agreed upon contractually by the relevant parties. Consider again the issue of the sale of a firm. The potential buyer will offer up to the present value of expected returns from acquiring the firm. The potential seller will weigh the value of the offer against the expected losses suffered by agreeing to a restriction on his future conduct. If the current owner of the firm (the potential seller) evaluates the offer as being worth more than the present value of these losses, his decision reflects a judgment about the value of his services 
in that industry. He is worth more outside the industry than in it. His customers are not being deprived of the services of a superior competitor. At least, that is the best judgment of the seller himself at the time of the deal. We can think of no reason why sellers' expectations would be systematically biased in this regard.

Third-party restraints cannot be presumed to be efficient from the perspective of any of the participants. They have not been voluntarily entered into by the affected parties. Assuming that anyone benefits, all others save the third party lose (in an ex ante sense) from the restrictions imposed by third parties. If effective, third-party restrictions on entry thwart resource owners from competing with protected firms. A monopoly grant prevents efficient competitors from offering their product on an equal footing.

We recognize that in a limited sense there is "competition" to be the monopolist, or to share monopoly power in a cartel. We believe that more confusion is sown than knowledge acquired, however, by describing political favorseeking as a competitive process. There is no reason to believe that superior entrepreneurs in the economic marketplace will win out in the political arena. There is good reason to believe the opposite, as the skills required for political and economic success are quite different (Hayek, 1944, Chapter 9). Further, special pleaders are a biased sample of businessmen, tending to be those who have failed to achieve their goals in the marketplace (Kolko, 1967).

Finally, as a factual matter, existing producers tend to be given monopoly rights in "grandfather" clauses. This is particularly objectionable from a process perspective. A major benefit of open markets consists of allowing entrants (and existing firms) to innovate or to recombine factors in imaginative ways. It is precisely this process that is stifled by monopolistic restrictions. Over the long run, static welfare losses pale in significance compared with this dynamic effect. Of course, these losses are inherently not measurable, and will accordingly be underestimated in any kind of particularistic weighing of costs and benefits. We can, moreover, rely on would-be monopolists to account for all possible benefits of any legal restriction. Arguments for tariffs are a classic example of this process. We know what the domestic industrialists gain. We can only imagine what we will all lose as consumers. Whenever public policy debates are conducted on such cost-benefit calculations, the argument will be tilted in favor of the proposed restriction and against open markets.

In recent years, Hayek (1973, pp. 55-71) has emphasized that public policy discussions must, for this and other reasons, be conducted on grounds of principle and not expediency. This, of course, means that discussions must be based on sound theoretical arguments, economic and noneconomic. We believe that a property rights theory of monopoly provides the economic part of these arguments by focusing on the systematic effects of alternative institutional regimes. For the same reason that individuals rely on rules in situations of general ignorance - the economy of information required - public policy discussions ought to focus more on comparative institutional analysis. 
Economics is simply not capable of providing the information needed to make case-by-case decisions, like that required in antitrust cases.

Regardless, then, of the soundness of our particular conceptualization of the monopoly question, we would argue for an institutional and property rights analysis of competition and monopoly. This shift in focus requires abandoning the institutionless analysis of neoclassical theory. In the last two chapters, we have offered a theoretical alternative to that theory.

\section{Notes}

1 The success of Allegheny Airlines (now US Air) in contracting out its commuter operations to smaller carriers should, in retrospect, have been accorded more attention by analysts. Allegheny's experience revealed the potential profitability of commuter operations. See Doty (1977).

2 On Piedmont's success, see Briggs (1981).

3 On United's strategy, see Business Week for April 13, 1981 (p. 49); August 17, 1981 (pp. 27-9); and October 19, 1981 (pp. 83-4). Also see Aviation Week \& Space Technology, August 24, 1981 (p. 30).

4 See O'Driscoll (1982, pp. 191-3); and more generally, the discussion in Letwin (1965).

5 Once the assumption of equilibrium was dropped, Arrow (1959) had to delve into a series of interrelated theoretical issues. These included, inter alia, the meaning of competition, expectations, pricing strategy and nonprice sources of information. All of these arose for "an objectively competitive market" (Arrow, 1959, p. 46). None are standard issues in the theory of competition, though all are on the agenda of questions that we have argued should be analyzed in micro theory. All these become critical theoretical issues once one abandons the assumption that prices are parametric. As Arrow (1959, p. 42) noted, "every relevant variable, except those classified as exogenous for the whole economic system, is the result of a decision on the part of some one individual unit of the economy." But as he concluded (p. 43), "Each individual participant in the economy is supposed to take prices as given and determine his choices as to purchases and sales accordingly; there is no one left over whose job it is to make a decision on price."

6 Competition to become or to replace an existing monopolist is no substitute for competition in an open market. The former involves striving to appropriate rents; resources expended in this process are expended solely to transfer income. Resources devoted to the pursuit of profits on competitive markets are expended at least in part to improve consumer satisfaction. In practice, of course, existing statutory monopolists are almost never dislodged by interlopers. Some franchised providers of cable TV services may be replaced in the coming years. Even were this to occur, it would not address the problems arising from the monopolistic provision of these services.

7 The literature on rent-seeking has given prominence to this and other issues in monopoly theory. Tullock (1967) and Posner (1975) helped initiate that literature. We would only suggest here that the rent-seeking literature fits better with a subjectivist analysis than with orthodox formulations.

8 II Peters 567. 